\title{
Integrating supply chain operations in the Internet era
}

\author{
Matopoulos, A., Manthou, V. and Vlachopoulou, M. \\ Department of Applied Informatics, University of Macedonia, 156 Egnatia st., 54006, Thessaloniki, Greece \\ Phone: $+302310891728 /+30231081893$ - Fax: +302310891804 \\ E-mail:arismat@uom.gr,manthou@uom.gr,mavla@uom.gr
}

\begin{abstract}
The internet's potential impact on supply chain operations is often approached in the literature in a quite generic way due to the complex nature of supply chains and the different levels of operations' integration. Drawing on existing research, this paper proposes an overall framework of supply chain integration and then attempts to provide a categorisation of the internet's role in the supply chain activities, providing insights from various sectors. The purpose of this paper is to describe and present the alternative ways that the internet impacts on the integration of supply chain operations, by comparing four different sectors: the automotive, the computer, the food and the grocery sector. The paper concludes that in the food, grocery and computer sector, internet's impact on supply chain operations has been quite poor, particularly forward integration, while it has been significant, in the backward integration of the automotive sector.
\end{abstract}

Keywords: integration intensity; internet; supply chain operations; supply chain management; SCM; supply chain integration; automotive sector; computing sector; food sector; grocery sector.

To cite this article:

Matopoulos, A., Manthou, V. and Vlachopoulou, M. (2007). Integrating supply chain operations in the Internet era, International Journal of Logistics Systems and Management, Vol. 3 No. 3, pp. 305-314.

DOI: 10.1504/IJLSM.2007.012995

\section{Introduction}

Successful companies seem to be nowadays, those that have carefully linked their internal processes to external suppliers and customers in unique supply chains (Frohlich and Westbrook, 2001, Boyer et al. 2004). In this effort towards linking internal processes to external suppliers and customers, the sharing of information among enterprises is absolutely critical. Electronic Data Interchange in the past and the last decade the Internet has enabled partners in the supply chain to act upon the same data (Christopher, 2005). This reality explains much of companies' initial enthusiasm, regarding the introduction of the Internet and Internet-based application in the early 
nineties. Companies' ultimate goal of process integration across the entire supply chain was now much more feasible than ever before.

In the literature, the role and the potential impact of Internet on companies and on supply chain operations are not questioned and have received significant attention. However, in many cases Internet's role on supply chain operations and its integration has been often approached in a very generic way (Cross, 2000; Auramo et al. 2004) and moreover, most of this research is carried out and is limited in knowledge and information high intensive sectors. In addition, much of the confusion arises as a result of the fact that the notion of integration is not very clearly defined yet. The complex nature of supply chains and the different levels of operations' integration that exist add significant difficulties in the understanding of the true impact of Internet. Consequently, what is the role of Internet on the integration of supply chain operations is not fully explored and understood.

This paper intends to increase the understanding of Internet's impact on supply chain operations. The objective is initially to propose an overall framework for supply chain integration, based on which the role of Internet is further examined in different business sectors, which is also the novel part of this research, since most of researches focus on a specific business sector which limits the applicability of the findings and the ability to generalize the results. Through secondary data research and literature review, the following research questions were investigated:

RQ1. What is the exact way that the Internet has affected the integration of supply chain operations?

RQ2. What is the impact of Internet on supply chain operations in different sectors? In other words, does the impact vary across different sectors and what are the reasons for this? 
Answering these two questions would empower the understanding regarding the real value of Internet for companies and particularly, whether or not this value applies, and in what way to different sectors.

\section{Intensity of integration: analysing the context of supply chain integration}

In order to identify the potential role of Internet on the integration of supply chain operations it is important to understand the concept of integration and its particular characteristics. In the literature, the concept of integration has been closely interrelated to supply chain management. As many authors argue (Gunasekaran and Ngai, 2004a; Pagell, 2004) the integration of all activities that add value to customers starting from product design to delivery is the cornerstone of supply chain management, and the performance of a supply chain is depended to a great extent to its level of integration (Stock et al. 1998). Despite the importance of supply chain integration, the concept itself is not very well defined and it is difficult to measure empirically (Frohlich and Westbrook, 2001), making it even more difficult to understand the role and the true impact of Internet on supply chain integration. To a great extent this is due to the fact that even for the relative concept of supply chain management, instead of a generally accepted definition, a plethora of approaches, sometimes conflicting, exists (New, 1996; Croom, 2000; Tan, 2001). Based on existing relevant literature, an overall research framework for supply chain integration is suggested (Fig. 1). The framework consists of three dimensions, which are analysed below, along with the managerial implications.

$<$ Insert Figure 1>

The first dimension in this framework is the direction of integration. It refers to the multitude of the entities and their place in the supply chain, in relation to the focal company. Based on the 
categorization provided by (Stevens, 1989), and Fawcett and Magnan (2002), three types-levels of integration exist, namely backward, forward and complete integration. Backward integration involves integration with valued first-tier suppliers or even second-tier suppliers. Analogously, forward integration involves integration with valued first-tier customers or even second-tier customers. Finally, complete integration, includes forward and backward integration from the “suppliers' supplier to the customers' customer". Managers who are responsible should first examine the characteristics of their supply chain in terms of the type of product which is moved and the type of entities participating. Product or partner constraints may put significant limitations in the direction of integration.

The second dimension in the framework refers to the extent of operations involved in the integration (width of integration). Fawcett and Magnan (2002), suggest that one way of dealing with the diversity of definitions is to concentrate on some of the core processes and functions related to the management of supply chains. Drawing from the literature (Giunipero and Brand, 1996; Cooper et al, 1997, Ross, 1998, Mentzer et al. 2001) these key business processes include not only basic logistics operations, such as procurement, inventory management, production planning, transportation, order processing, customer service but also marketing, promotion, sales, product design and new product development, processes, which expand the organisational boundaries of individual companies. It is clear, that integration may not be applicable to all supply chain operations and moreover, may not be applicable in the same way for different sectors. Again, managers who are in charge should be in position to evaluate the strengths of each participant in their supply chain and to identify what are the operations where integration is feasible. 
The third dimension in the framework considers the level of integration based on one of the most widely accepted proposed decision taking levels, the strategic, the tactical and the operational level. At the strategic level it is important to identify what are the long range aspects of integration. For example, if the competitive strategy of a firm has changed due to the integration of operations. The tactical level includes medium term aspects and finally, the operational level includes day to day decisions and actions. Managers should be able to identify what is the level of commitment and involvement of each partner in the supply chain. For example, companies that focus on the operational aspects of integration are less likely to invest on technologies which may alter their way of conducting business (new business models apart from the traditional).

\section{Assessing the role of Internet on supply chain integration: approaches and critical aspects}

More than a decade after the introduction of the Internet, Internet-based applications are not anymore jargon for companies. Companies' initial enthusiasm has been transformed in scepticism and in some cases even in negativism, as companies often find difficulties in quantifying or even clarifying the role and the benefits of Internet. Under this prism, assessing the role of Internet on supply chain integration becomes very important. Analysing the role of Internet on supply chain integration means essentially to analyse its impact on the direction of integration, on supply chain operations and on the level of integration.

The plethora of approaches, sometimes conflicting, of the content of supply chain management, has inevitably led to a number of different views regarding the impact of Internet on supply chain operations. In the logistics/supply chain context, Bowersox and Daugherty (1995), outlined that IT is key in supporting companies creating strategic advantage by enabling centralized strategic planning with day-to-day centralized operations. One way of dealing with the diversity of definitions is to 
concentrate on some of the core processes and functions relating to the management of supply chains - namely sales and marketing, fulfilment (i.e. logistics, warehousing and distribution) operations planning and procurement. Naturally, this is not an exhaustive approach, and it can provide sufficient scope for analysis of the key initiatives being undertaken by organisations in their supply chain (Croom, 2005).

Many authors have approached Internet's impact on supply chain management under the revenue-cost prism (Basu and Siems, 2004; Williams et al. 2002). Under this aspect, Internet may increase company's revenues by expanding its customer base and the commercial channels, by offering completely new products and services. Regarding cost reduction, it arises as companies improve a number of business processes in the supply chain, mainly by achieving higher levels of coordination due to more efficient information exchanges. Other authors (Cross, 2000; Auramo et al. 2004) take a less tangible approach by focusing on the qualitative benefits of Internet. These benefits include facilitated transaction execution, better coordination and collaboration and enhancement in the decision support process.

Despite the variations in defining the content of supply chain management it is widely accepted that managing the supply chain to a great extent deals with business processes, as well as flows (information, product, capital, knowledge) and business relationships. Assessing the impact of Internet on supply chain operations on a revenue-cost basis is not always practical. A processbased approach is more likely to present the real value of Internet not in a generic way, avoiding overestimations or underestimations of its real value. However, the problem is that not all processes can be transformed to some type of profit-based relationship. On the other hand, focusing only on processes and on operational improvements may be a problem, since other less measurable values may be missed. It is rather impractical and impossible to materialize non 
material based improvements, such as information flow improvements, or even modifications in business relationships.

\section{Internet affected supply chain integration: evidence from various sectors}

In general, the Internet has been identified by the vast majority of researchers as an enabling force for improved supply chain management, offering efficiency and cost reduction to business processes across industries and nations. However, in this part of the paper, an identification of the role of the Internet and its impact on supply chain integration is attempted in industry-specific context. Based on the overall framework of integration presented in a previous part of the paper, an exploration of the Internet's impact follows. The industry specific context facilitates the identification of the real weaknesses and strengths of Internet in different sets of business environment and the type of integration that has been achieved. The business sectors that have been selected for exploration are: the automotive industry, the computer industry, the food industry and the grocery industry. The logic behind this selection was initially to include sectors with economic importance. Additionally, all four sectors have been to a great extent global and represent knowledge and information high (computer and automotive industry) and low (food and grocery industry) intensive sectors. Finally, the availability of relevant data for those sectors was another important element.

\section{1 Evidence from the automotive industry}

During the last decade the automotive industry is in the process of globalization in an effort to confront with global over capacity, rising stock levels and low profitability (Palm and Sihn, 2005). The element of time has become now the crucial issue, with manufacturers aiming to achieve the 
five-day-car project. In addition, most of the manufacturers are facing the challenge of extending their production plans to different places than the traditional US-Japan-Europe triad (Lung, 2000). These changes have resulted in an undisputed need for integrating supply chain operations beyond companies' boundaries and the role of Internet on supporting this integration has been rather important. In particular, regarding the direction of integration in the automotive industry, the Internet has allowed for forward integration with customers getting more knowledge than even before regarding products and services they are considering purchasing (Handfield and Nichols, 2002). Most of automotive manufacturers have built powerful websites allowing customer to reach any of their products. Backward integration is a given in the automotive industry due to the use of Internet which enables not only first-tier suppliers (as in the past with the use of Electronic Data Interchange), but also second and third tier suppliers to have access on production schedules and plans (Handfield and Nichols, 2002). Regarding the width of integration, the Internet has extended the processes upon which suppliers and customers do collaborate. The last years, first tier suppliers have taken more status, and their roles in the supply chain have been extended from the traditional activities related to material flow, sourcing, to more complex activities, such as new product design (Palm and Sihn, 2005; Neto and Pires, 2005). Customers from their side can also have access not only on prices, but in some cases become active parts in the manufacturing process by selecting colour, type of seat covers etc. For example, BMW allows customers to make changes to their vehicle and moreover, within 6 days of final assembly (Gunasekaran and Ngai, 2004b). Even the level of integration in the automotive industry has been shifted from operational and tactical to strategic with manufacturers communicating via Internet with executives from divisions all over the world, taking decisions on product development, market and pricing issues (Handfield and Nichols, 2002). 


\subsection{Evidence from the computer industry}

The computer industry is a very competitive industry with powerful manufacturers competing on a global basis and being the most important players of the industry. Similar to the automotive, time pressures are also characteristic of the industry, even more crucial. Apple Computer for example, was unable to fill orders for its new high-end line of G4 computers because of delays in the supply of chips, experiencing a devastating 14\% drop in revenue in 1999 (Gunasekaran and Ngai, 2004b). Time-based competition has emerged as the winning strategy in the fast-cycle computer industry, where product life cycles are relatively short (two years or less) and computer products becoming obsolete in shorter time than before (Rosas-Vega, and Vokurka, 2000). The main characteristic of the computer industry is the fact that most of the manufacturers are using more or less the same components and thus, the competition game is mainly played on the basis of cost and customization, rather than on service and innovation, since manufacturers can not realize unique value from common suppliers. As a result, manufacturers continue a relentless pursuit of cost reductions and operational improvements, to drive supply chain efficiencies and to confront the continuing drop in retail prices and distributor margins. In their effort to achieve integration and thus, improvements the role of Internet has been quite important. In fact, most computer manufacturers have only managed so far backward integration, while the width of integration remains very limited to a few activities when it comes to forward integration, with Dell so far being a successful exemption (Boyer et al. 2004).

\subsection{Evidence from the food industry}


A number of changes have occurred the last decade in the food industry. The entrance of global retailers, industry's consolidation, changing consumer consumption attitudes, as well as, the existence of more strict regulations and laws regarding food production as a result of the recent food crises (Hughes, 1994, Kaufman, 1999, Fearne et al. 2004), have altered the business environment for most of the companies operating in the sector, encouraging integration and improvement attitude. The impact of Internet on supply chain integration has not been very important. Food manufacturers have not managed to achieve complete integration. In particular, backward integration with the use of Internet has been weak, as most of their suppliers are smallmedium size companies, such as, farmers, producer groups, cooperatives which have not adopted Internet-based applications (European Commission, 2002). Forward integration has been more intense at the retailer level, given the size of these companies, but not at the consumer level, which essentially remains at a distance and isolated from food production (Kaufman, 1999; Fearne et al. 2004; GMA, 2000). The width of integration has not been quite extended with companies using the Internet mainly for logistics activities, rather than on new product development and relevant activities (King, 2001). This is also due to the fact that innovation and new product development is still conducted at the manufacturer level and has not been passed to its suppliers, which are usually growers and co-operatives, as in the automotive industry. As far as the impact of Internet on the level of integration, it has been very poor, with big manufacturers scheduling in short or mid term, plan forecasts and promotion plans (e.g. the use of the CPFR platform).

\subsection{Evidence from the grocery industry}

The grocery industry is one of the most important industries presenting some interesting characteristics. Groceries are perhaps, the most universal commodity, thus, competition along 
with varying customers' tastes, perishable nature of products, often spurs supermarkets to go to great lengths to develop new technologies and methods of streamlining both their supply chain efforts (Boyer and Hult, 2005). In such an environment, the role of Internet would be in theory to link customers with grocery stores from their homes and will help integrate the supply chain backwards by closely linking marketing, sales, operations, and logistics (Boyer et al., 2004). However, so far both backward and forward integration does not seem to work in the grocery industry. In fact, in some cases forward integration by big grocers was restraint, due to problems in backward integration with their suppliers and Webvan company's problems are a good example (Boyer et al., 2004). Regarding the width of integration, the impact of Internet has been quite limited to coordinating some logistics activities and communication. Only lately, Sainsbury, one of the biggest UK retailers developed a package, which aims at reducing new product development up to a third of the traditional time. The retailer aims at linking over its website, a number of entities involved in the new product development process, such as: chefs, concept developers, manufacturers, buyers, technologists, nutritionists, marketeers, design studios, artwork and reproductive houses, product safety and legal experts. Using this system all parties can access the data on line as needed e.g. a technologist on a supplier visit in South America can $\log$ on and approve packaging details on line keeping the project on time. Using the website means that everybody working on the project, no matter where they are in the world, is using the same version of information at any point in time, so for example if an ingredient was changed by the chef an e-mail would be sent to the packaging designer alerting them to alter the packaging too. This will reduce mistakes that slow down the launch of products (Sainbury, 2002). 


\section{Conclusions - Discussion}

This paper has investigated the issue of supply chain integration and the respective role of Internet by initially developing an overall framework. The framework identified three major aspects of supply chain integration which should be taken into consideration in order to assess the role of Internet. Assessing the real value of Internet on supply chain operations is particularly important since in many cases it may be overestimated being responsible for the Internet "euphoria". Kanter (2004), very accurately argues that it is only now where the unrealistic hype about the Internet passes away that the potential of the Internet can emerge.

Based on the overall framework developed, the paper aimed at analysing and exploring the role of Internet on the integration of supply chain operations by providing insights from different business sectors. In some of the sectors explored, the impact of Internet on the integration of supply chain operations proved to be more of a theoretical ideal than a business reality. This was particular the case in the food and grocery industry, where the impact of Internet on supply chain operations has been quite poor particularly forward integration. The main reason for this situation is related to the fact that many of the companies operating in both sectors are more Small-Medium size companies lacking in financial and human resources. In addition, a significant constraint is related to the nature of the products. On the contrary, in the automotive sector the role of the Internet on complete integration has been significant, particularly backward integration. Finally, in the computer industry, Dell Company still seems to remain the sole example of how complete integration can become reality with customers becoming parts of the extended enterprise.

This research has several constraints related to availability of data, which limits the ability to generalise the findings and conclusions. An more in-depth analysis of the sectors examined, as 
well as further analysis of other business sectors may be also needed. This will allow for generalizations to be drawn and more accurate and measurable assessment of the impact of Internet on supply chain integration.

\section{References}

Auramo, J., Kauremaa, J. and Tanskanen, K. (2004) Benefits of IT in supply chain management an explorative study of progressive companies, Available at: http://www.tuta.hut.fi/logistics/publications/IT_in_SCM.pdf (accessed 05/06/2005).

Basu, A. and Siems, T.F. (2004) The impact of e-business technologies on supply chain operations: $A$ macroeconomic perspective, Research Department Working Paper 0404, Federal Reserve Bank of Dallas, Available at: http://www.dallasfed.org/research/papers/2004/wp0404.pdf. (accessed 05/06/2005).

Boyer, K.K., Frohlich, M.T. and Hult, T.G. (2004) Extending the supply chain: how cutting edge companies bridge the critical last mile into customers' homes, American Management Association, New York, US.

Boyer, K.K., and Hult, T.G. (2005) Extending the supply chain: integrating operations and marketing in the on-line grocery industry, Journal of Operations Management, Vol. 23, No. 6, pp. $642-661$.

Bowersox, D.J., Daugherty, P.J. (1995) Logistics paradigms: the impact of information technology, Journal of Business Logistics, Vol. 16, No. 1, pp. 65-80.

Cooper, M.C, Lambert, D.M. and Pagh, J.D, (1997) Supply Chain Management: More than a new name for logistics, The International Journal of Logistics Management, Vol. 8, No. 1, pp. 1-14.

Christopher, M. (2005) Logistics and supply chain management: creating value-adding networks, $3^{\text {rd }}$ edition, Pearson Education Limited, Great Britain. 
Croom, S.R. (2000) The impact of web-based procurement on the management of operating resources supply, The Journal of Supply Chain Management, Vol. 36, No. 1, pp. 4-13.

Croom, S.R. (2005) The impact of e-business on supply chain management: An empirical study of key developments, International Journal of Operations \& Production Management, Vol. 25, No.

1, pp. 55-73.

Cross, G.J. (2000) How e-business is transforming supply chain management, The Journal of Business Strategy, Vol. 21, No. 2, pp. 36-39.

European Commission, (2002) ICT and e-business in the Food, Beverage and Tobacco Industry, European e-business Market Watch, Sector report, No. 1/July 2002.

Fawcett, S. E. and Magnan, G. M. (2002) The rhetoric and reality of supply chain integration, International Journal of Physical Distribution \& Logistics Management, Vol. 32, No. 5, pp. 339361.

Fearne, A., Hughes, D. and Duffy, R. (2004) Concepts of collaboration-supply chain management in a global food industry, Available at: http://www.imperial.ac.uk/agriculturalsciences/cfcr/pdfdoc/global-food-industry.pdf ～(accessed 10/09/2004).

Frohlich, M.T. and Westbrook, R. (2001) Arcs of integration: an international study of supply chain strategies, Journal of Operations Management, Vol. 19, pp. 185-200.

Giunipero, L.C. and Brand, R.R. (1996) Purchasing's role in supply chain management, The International Journal of Logistics Management, Vol. 7, No. 1, pp. 29-37.

GMA, (2000) Food manufacturers take first step toward real B2B e-commerce for grocery industry, Available at: http://www.gmabrands.com/news/docs/NewsRelease.cfm?DocID=615\& (accessed 05/07/2005) 
Gunasekaran, A. and Ngai, E.W. (2004a) Information systems in supply chain integration and management, European Journal of Operational Research, Vol. 159, pp. 269-295.

Gunasekaran, A. and Ngai, E.W. (2004b) Build-to-order supply chain management: a literature review and framework for development, Journal of Operations Management, Vol. 23, No. 5, pp. 423-451.

Handfield, R.B. and Nichols, E.L., Jr. (2002) Supply Chain Redesign: Transforming Supply Chains into Integrated Value Systems, Upper Saddle River, NJ, Prentice Hall.

Hughes, D. (1994) Breaking with Tradition: Building Partnerships and Alliances in the European Food Industry, Wye, Wye College Press.

Kanter, R.M. (2004) How to evolve: leading change in the digital age, Foreword in: "Process Management for the Extended Enterprise" (authors: Tonchia, S. and Tramontano, A.), Springer. Kaufman, P. (1999) Food retailing consolidation: Implications for supply chain management practices, Journal of Food Distribution Research, March, pp. 6-11.

King, R.P (2001) The new logistics, The Retail Food Industry Center, University of Minnesota, Available at: http://web.mit.edu/ipc/www/pubs/articles/king.pdf (accessed 05/07/2005)

Lung, Y. (2000) Is the rise of emerging countries as automobile producers an irreversible phenomenon? In: Humphrey J, Lecler Y, Salerno M.S., Global strategies and local realities: the auto industry in emerging markets, Macmillan, London.

Mentzer, J.T., De Witt, W., Keebler, J.S., Min, S., Nix, N.W., Smith, C.D. and Zacharia, Z.G. (2001) Defining supply chain management, Journal of Business Logistics, Vol. 22, No. 2, pp. 1-24. Neto, M.S. and Pires, S.R.I. (2005) Production organization, performance and innovations on the supply chain management within the brazilian automotive industry, In Proceedings of the 3rd 
International Workshop on Supply Chain Management and Information Systems, (Eds. Ketikidis, P. and Koh, L.), Thessaloniki, 6-8 July, Greece, pp. 101-110.

New, S.J. (1996) A framework for analysing supply chain improvement, International Journal of Operations and Production Management, Vol. 16, No. 4, pp. 19-36.

Pagell, M. (2004) Understanding the factors that enable and inhibit the integration of operations, purchasing and logistics, Journal of Operations Management, Vol. 22, pp. 459-487.

Palm, D. and Sihn, W. (2005) Agility in the automotive supply chain, In Proceedings of the 3rd International Workshop on Supply Chain Management and Information Systems, (Eds. Ketikidis, P. and Koh, L.), Thessaloniki, 6-8 July, Greece, pp.13-20.

Rosas-Vega, R. and Vokurka, R. (2000) New product introduction delays in the computer industry, Industrial Management and Data Systems, Vol. 100, No. 4, pp. 157-163.

Ross, D.F. (1998) Competing through supply chain management", New York, Sainsbury, (2002) Food products to be developed on the internet, Available at: http://www.jsainsbury.co.uk/index.asp?pageid=322\&subsection=news_releases\&Year=2002 (accessed 05/07/2005)

NY, Chapman and Hall.

Stevens, G.C. (1989) Integrating the supply chain, International Journal of Physical Distribution and Materials Management, Vol. 8, No. 8, pp. 3-8.

Stock, G.N., Greis, N.P. and Kasarda, J.D. (1998) Logistics strategy and structure: a conceptual framework, International Journal of Operations and Production Management, Vol. 18, No. 1, pp. 37-52.

Tan, K.C. (2001) A framework of supply chain management literature, European Journal of Purchasing and Supply Management, Vol. 7, No. 1, pp. 39-48. 
Williams, L.R., Esper, T.L. and Ozment, J. (2002) The electronic supply chain, International Journal of Physical Distribution and Logistics Management, Vol. 32, No. 8, pp. 703-719.

\section{FIGURE CAPTIONS}

Figure 1: An Overall Framework for Supply Chain Integration

\section{FIGURES}

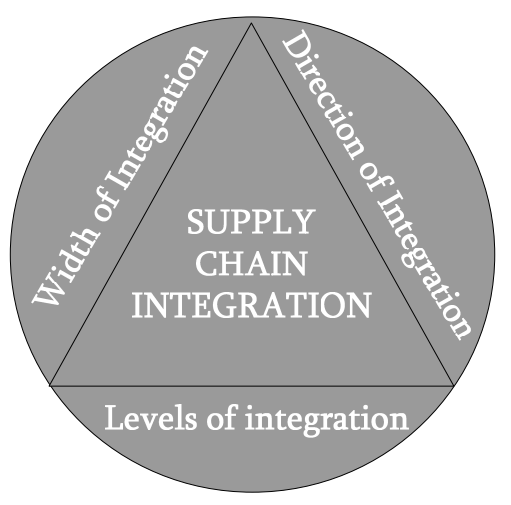

Figure 1 